\title{
Principles of creating a system of sustainable water use in Ukraine
}

\author{
Nataliia Kovshun ${ }^{1, *}$, Nataliia Savina ${ }^{1}$, Mamadou Alouma Diallo ${ }^{2}$, Nina Kushnir $^{1}$, Dong Zhiwei ${ }^{3}$, and Vitalii Zoshchuk ${ }^{1}$ \\ ${ }^{1}$ National University of Water and Environmental Engineering, 33028, Rivne, Ukraine \\ 2 Carmels Research Institute, 10500, Médina Dakar, Senegal \\ 3 355100, Songcheng, China
}

\begin{abstract}
This research focuses on the problem of water supply, and its solution requires scientific and practical approaches in environmental, engineering, economic and other fields. Practical recommendations to create an integrated water use system in Ukraine are based on the delimitation of its target subsystems. Special attention is paid to an integrated approach to water resources management, identification of key issues, clear conceptual modeling, strategy development, and production of 'useful' scientific information. It is important to study the role of coordinating government bodies in the field of water space monitoring. In particular, this mechanism involves the development of national program for monitoring the aquatic environment, the formation of budgets of all bodies and institutions; search for additional sources of funding and organizational methods. An important tool for improving the state of water resources is the implementation of international environmental standards and conventions. These strategic decisions are entrusted to the Ministries of Environment and other governing bodies. The use of software products generate significant amounts of data accumulated in various information banks. The main direction of the study is the concentration of information data in one key database. It will provide clear assess to the data aquatic environment and make analytical studies.
\end{abstract}

The problem of interaction between society and nature is one of the most important issues of humanity. It has required a lot of effort of scientists and practitioners in the environmental, engineering, economic and other fields. The results of previous public research [1-3] are significant progress in this direction: the transfer of environmental information has become much better, environmental monitoring and special studies in various fields of ecology and water use, a number of changes in environmental legislation in accordance with international agreements and conventions. However, it should be noted that despite the desire to improve the environmental situation, society still suffers from anthropogenic pressure.

The problem of water supply needs special attention. Saving of water resources and rational water use is the key to further economic growth and social welfare. Growing freshwater shortages and changing climates are increasingly comprehended as a major risk to the global economy [4]. Scientists point out the need for transition to sustainable water use, which requires appropriate government regulation, business sector initiatives, consumer responsibility $[5,6]$. Significant progress in solving water use problems has been the concept of integrated water resources management. It has a number of shortcomings, but it is the basis for many environmental policies, strategies and management systems.

Taking into account the existing scientific achievements, we have shaped the main tasks for building a system of sustainable water use in Ukraine.

In this study, the system of sustainable water use is considered as a complex system that includes a set of simpler, to some extent isolated from each other subsystems with a clear hierarchy of goals, principles and mechanisms of interaction. We consider it expedient to differentiate the development and substantiation of practical recommendations for the creation of a system of sustainable water use in Ukraine according to its five target subsystems. These include the following:

1. development and ensuring the effectiveness of the water source;

2. modernization and ensuring the reliability of water management;

3.rationalization and efficiency of water use in resource constraints;

4.improvement of information and methodological support of water management processes;

5.certification of industries and technologies, as well as regions for the effectiveness of water management.

Sustainable water use requires integrated management. At the same time, special attention should be paid to the definition of key issues, clear conceptual

\footnotetext{
* Corresponding author: n.e.kovshun@nuwm.edu.ua
} 
modeling, strategy development, scenario analysis, production of 'useful' scientific information [7].

To ensure the effectiveness of the first subsystem 'Development and effectiveness of the water resources' we have identified problems that need to be addressed and proposed appropriate measures. For example, there is a significant problem of cooperation between the Ministry of Environment and other ministries, state committees and parliamentary committees, as well as with regional and local authorities. Complex and lengthy procedures do not promote cooperation in the development of legislative projects. Therefore, in our opinion, the National Environmental Action Plan should be revised and refined to take into account the prospects of implementing a sustainable water use system in order to set clear priorities, goals and time frames in different sectors of environmental protection. This needs to be done in close cooperation with other ministries and stakeholders.

Despite the fact that the correlants of the Ministry of Environmental Protection of Ukraine are aware of the importance of international legislative instruments, the urgency of implementing the provisions and compliance with new norms and action plans, however, the latter is not a priority for this institution. A serious analysis of water use needs will clarify the objectives and ensure clear implementation of the obligations of related ministries and agencies. To improve the situation in this area, strategic plans for the implementation of agreements should be developed and agreed together with proposals for ratification, their implementation should follow the integration of international obligations into national law and include financial obligations to implement and comply with the provisions of Association Agreements of Ukraine with EU Member States. In addition, strategies and strategic plans need to focus on defining and justifying realistic goals, rather than developing unrealistic programs within the 'doctrinal foundations of sustainable development'.

The NGO sector includes not only independent organizations but also former state-supported research institutes. The current Public Council does not appear to be representative enough to be the Ministry's only partner for public consultation. Because of the Chernobyl accident, public environmental concerns and interest remain relatively, high compared to many other Central and Eastern European countries, although environmental protection does not seem to be a top priority given the problems of the economic crisis. Therefore, the Ministry of Environmental Protection of Ukraine should strengthen its coordination activities on environmental monitoring. Complete and coherent national monitoring systems need to be developed, which should be preceded by consistency of data systems and methodologies. Data needs to be systematized, integrated and prepared for management decisions. The European Environment Agency must be provided with aggregated data. Work on the development of an adequate information system should be accelerated in order to increase public and government concerns about environmental issues.

The Ministry can strengthen its position in public if it succeeds in meeting the high social interest in solving environmental problems. Although some laws provide for public participation, it is not significant in the environmental field, as adequate procedures are not developed. The expected ratification of the Aarhus Convention is the right step, which, however, cannot replace the procedural grounds for public participation. The Ministry of Environment should improve public access to environmental information in accordance with the Aarhus Convention and seek closer contacts with the entire NGO sector, including in the development of laws, policies and programs. Appropriate methods for enhancing public participation should be adopted in consultation with NGOs. Environmental impact assessment should be seen as one of the mechanisms to increase public participation in the decision-making process. The ministry must determine its contacts with the press. The public should be encouraged to exercise their environmental rights, and the development of procedures for public participation in environmental decision-making should be accelerated.

Although Ukraine is already a part of many international conventions, several have not yet been ratified, including the Convention on the Transboundary Effects of Industrial Accidents, the Convention on Cooperation for the Protection and Sustainable Use of the Danube River Basin and some protocols to the Convention on Long-range Air Pollution. Ratification of these agreements can be a tool for further development and strengthening of comprehensive environmental policy and legislation and international cooperation in these fields. Considering the ratification of these conventions as soon as possible, it should be borne in mind that a full and realistic assessment of their consequences is a prerequisite. The National Commission for Sustainable Development needs to intensify its activities. Meetings of the Commission should be regular so that it becomes an effective tool between sectoral coordination of environmental issues. Together with the world community, Ukraine should produce and consume ecosystem services [8].

Biogens and petroleum products, which come mainly from onshore local sources of pollution through rivers, undermine the environment of the Black and Azov Seas. Despite the significant number of water treatment facilities located in the coastal zone, a significant amount of untreated and incompletely treated industrial and domestic wastewater is still discharged into the sea. Largely, this pollution is a consequence of unsatisfactory technical condition and reduced efficiency of treatment facilities, as well as frequent accidents on sewerage networks and treatment plants. The reasons for this situation - mainly financial - stem from the general economic difficulties in the country. However, in the interests of marine water protection, sewerage networks and treatment facilities need to be repaired and upgraded immediately. Funding can be temporarily secured through mandatory contributions from profitable economic activities in the coastal zone.

The Ministry of Environmental Protection of Ukraine should build up its role as a coordinating governmental unit in the field of marine environmental monitoring. In particular, it should develop a mandatory overall national marine monitoring program and participate in the 
budgeting of all monitoring bodies and agencies; and ensure that other sources of funding and organizational arrangements are sought.

Ukraine has a significant number of water quality standards, which in some cases are very strict. This leads to a rather complex permitting system, which undermines the application and overloads the understaffed regulators. Therefore, the Ministry of Environmental Protection must ensure the coordination of monitoring programs, as provided for in Resolution № 391 (1998). The number of water quality standards needs to be lowered and they need to be implemented at true levels to enable their practical application.

Surprisingly, there are no formal consultations between national, regional and local authorities within the river basin. Such cooperation could help the overall cooperation between these bodies and would clearly contribute to a more coordinated management of water resources in the basin. These provisions should be taken into account when preparing the Ministry of Environmental Protection of Ukraine new proposals for the basin council for the implementation of the National Program for the restoration of the Dnieper basin and improving the quality of drinking water. The relevant draft resolution of the Cabinet of Ministers was sent for consideration to all interested national and regional authorities, scientific and environmental organizations. For each significant river basin, administrative bodies and committees should be established, and the principle of integrated water management should be implemented at the basin level. All national, regional and local authorities involved should be involved, if possible with international partners (e.g. the Republic of Moldova in the case of the Dniester). The institutional responsibility of the basin structure for water management should be supported by adequate financial funding so that water management objectives, particulary for wastewater, can be achieved at the local level. Financial revenues in the form of water payments collected in the basin should be used to improve water management in the same area.

It is known that in general, the quality of surface water is inappropriate for drinking, which is a consequence of pollution from municipal and industrial effluents, diffuse pollution from agriculture and the atmosphere. This problem cannot be solved in the nearest future. Groundwater is less vulnerable. Therefore, addressing the practice of using groundwater for drinking seems to be completed and balanced task; however, its solution requires modernization not only of the water complex, but also of the national economy in general.

Surface and underground hydrosphere is one of the important factors in the evolutionary development of the biosphere and man, its natural mechanisms and the preservation of their sustainable impact will contribute to the safe development of the economy and the state as a whole. A thorough analysis of the domestic structure of water use and its technical and economic indicators shows the low perfection of technological, environmental and existing regulatory mechanisms. There are 200 different regulations in this area, which are mainly of a recommended nature. In addition, a significant part of them is based on the use of different methodological principles and is not focused on the agreed levels of waterecological assessments of surface and groundwater bodies, landscapes, natural and man-made systems, etc.

In order to arrange and implement a set of measures in the context of ensuring the effectiveness of the subsystem 'Modernization and ensuring the reliability of water production' we have proposed the following recommendations.

The responsibility for implementing international environmental standards and conventions lies primarily with the Ministry of the Environment. However, in many cases, ministries such as the Ministry of Finance, the Ministry of Economy, and the Ministry of Agriculture must also be involved. Ukraine does not properly analyze the effectiveness of international environmental assistance. A special center for environmental project management should become a tool at least for obtaining such valuable information, as well as for improved project management. Cooperation with the National Agency for Development and European Integration is essential in this regard. Implementation, compliance and application of environmental norms and action plans in relation to existing international obligations should be a priority of Ukraine's environmental policy. Plans for ratification of new international environmental legislation should include an assessment of the cost of implementing them. Ukraine needs to continue working on ratifying all major international environmental conventions in line with national priorities. It should be borne in mind that some industries are special and need separate consideration. For example, the mining industry, which in Ukraine is almost not included in the system of sustainable water use. Instead, in the world this problem is raised [9].

In order to improve water management, the principle of river basin management needs to be further implemented. National action programs have already been developed for some river basins, such as the Dnieper. In developing the National Program for the Restoration of the Dnieper Basin and Improving the Quality of Drinking Water, the role of regional and local authorities was limited to providing information (suggestions) about the Dnieper to national authorities. Of course, measures taken (or not taken) from below will affect the measures proposed from above. The responsibility of water management bodies and the development of standards need to be streamlined. A clear responsibility for coordination should be defined and a mechanism for such coordination established. The establishment of a national body to unify standards and methods, i.e. the standardization body, needs to be considered.

Water consumption in Ukraine is quite high. At the same time, water prices for utilities and industry are relatively low. This is not surprising, as Ukrainian, law states that water is the exclusive property of the people of Ukraine, and water use is free. Only water supply, sewerage and wastewater treatment are paid moderately. However, this fee does not fully reimburse all costs, including investment. Significant efforts are needed to recoup the investment, maintenance and operation of water supply systems. Increasing tariffs for water use and discharges are important steps to ensure adequate funding 
for water infrastructure, such as the reconstruction of water treatment plants. Determining the price of water, which would fully reimburse the relevant costs, and the installation of water meters to detect the volume of its actual consumption would save significant amounts of water. At the same time, users' accounts are hardly affected by these measures, as they should pay a higher price but consume less. Such measures would help to improve the operation of treatment plants, as they would receive less water for processing. Therefore, the introduction of best available, low-cost technologies and / or technology-based emission standards should form the basis of pollution reduction strategies. For the construction and operation of sewerage networks and water treatment facilities, new financial support mechanisms adequate to real processes should be formed, with clearly defined responsibility of polluters.

To improve the efficiency of wastewater treatment, further training of personnel on the operation of facilities and equipment and process control is needed. Responsibility for urban wastewater management and sewage disposal should be clearly defined. Preference should be given to the use of silt in the form of fertilizers [10].

At the same time, the EU Directive on urban wastewater and the use of sludge in agriculture should be followed. In addition, trained personnel should manage treatment plants. Low professional level of staff is a common problem. Special training on the operation of facilities and equipment and process control could significantly improve the efficiency of treatment facilities. There is an urgent need for Ukraine to increase the level of professionalism and professional training of staff and management entities that take care of water use problems.

In order to improve the management of the marine environment, it is necessary to define clear environmental policy objectives and include them in the national program for the protection and restoration of the Black and Azov Seas. A wide network of administrative and scientific institutions has been formed to facilitate the management of the marine environment. At the same time, the developed institutional capacity at the regional and local levels cannot compensate for the lack of a specialized management structure at the national level. To improve the coordination of the efforts of numerous institutions aimed at improving the effectiveness of the protection of the marine environment, the Ministry of Environmental Protection of Ukraine should establish a special structural unit for the protection of the Black and Azov Seas.

Shipping and related activities are a major source of marine pollution, especially gasoline hydrocarbons. Another significant threat to the marine ecosystem is the penetration of exotic species, most often by removing ballast water. That is why it is necessary to develop special recommendations and implement appropriate measures.

Ecological optimization and sustainable development of the water management complex are and should be the main direction of improving the environmental parameters and safety of water bodies. The previous development of the water management complex of Ukraine on the principles of their maximum importance in economic circulation has led to destructive changes in water resources systems, deterioration of environmental parameters (hydrosphere, biosphere, lithosphere, atmosphere). To fundamentally improve the ecological level of water use within Ukraine, it is recommended to develop technological, regulatory and other documents based on the principles of maximum allowable waterecological changes or loads.

In accordance with the provisions of the National Water Code, funds from the fee for water intake and discharge of wastewater into water bodies of local significance are paid to the local budget. Funds from the fee for water intake go to the national $(80.0 \%)$ and regional budgets $(20.0 \%)$. However, the majority of the population receives water from public facilities and most of the money goes to the state budget, while investment, operating costs and maintenance of water supply, sewerage and treatment systems must be provided at the local level. Therefore, a more balanced decentralization of responsibilities and budgets seems to be a prerequisite for more efficient water management.

In order to ensure the effectiveness of the subsystem "Rationalization and increase the efficiency of water use in resource constraints" we have made the following proposals.

There are a significant number of standards - in fact, thousands that cannot be tracked for both technical and economic reasons and compliance with which remains problematic. Therefore, from all points of view, it would be useful, taking practical expediency, to take appropriate legal and organizational measures to establish and apply standards. This requirement can be met relatively easily, as it requires virtually no funds. On the contrary, it would reduce costs. Therefore, it is necessary to identify effective economic tools for the introduction of the "polluter pays" principle. Research is needed to prepare for the transition to a clearly market-oriented fiscal and economic policy. It is important to find out what levels of environmental payments will be possible and effective and what time frames are needed to implement them.

The main problems exist in the field of financing environmental measures. The fundamental problem of creating a viable system of public revenues in Ukraine is the further complication of the situation with environmental expenditures, as there are more urgent priorities. Even more, the approach to solving the problem, which is to allocate certain categories of public revenues for environmental purposes, is not easy to apply, which creates limited transparency. Statistics on environmental expenditures, including funding sources, need to be improved.

The difficult financial situation is forcing more and more importance to be attached to foreign aid. The experience of other countries with weak economies shows that the management of environmental projects that have components of foreign aid often benefit much more from more specialized and effective administrative measures. The presence of a separate special center in the structure of environmental management, as a rule, contributes to the strengthening of environmental components in general 
assistance programs or projects. It also gives a better idea of all international environmental assistance and is therefore more useful for the process of setting national priorities in environmental policy. The activities of such a center should be coordinated with the National Agency for Reconstruction and European Integration. Among other things, the center transparently and efficiently should accumulate funds from environmental payments.

In modern conditions, it may be appropriate to consider the introduction of a national environmental fund and local environmental funds in order to manage both revenues and expenditures for environmental protection with the help of appropriate supervisory boards. Regional funds can be created by consolidating local funds, which should finance the costs of local environmental measures. Proceeds from such funds should come mainly in the form of environmental taxes, fees and penalties, as well as foreign aid.

Most cities and towns in Ukraine use treatment facilities for municipal and industrial wastewater. The quality and efficiency of wastewater treatment could be improved by increasing the capacity and technical condition of existing facilities. In particular, reducing water consumption would improve the operating conditions of treatment plants, as reducing the amount of wastewater would make it possible to process them more efficiently. This provision applies to both water treatment plants and treatment plants. In addition, the practice of sewage treatment is unsatisfactory and needs to be streamlined. These mules can never be returned to the rivers. The best option is to use them as fertilizers, provided that the metal content does not exceed the established limits. This means that some industrial wastewater must undergo a pre-treatment stage in order to remove toxic elements or not enter the treatment plant at all, but be treated in another way.

It should be noted that external water quality standards are currently used to calculate the maximum permissible discharges of pollutants from industry into water bodies, although technologies that do not require additional funds have not yet been defined and provided for by the National Water Code. The rational aspect of the standards required for Ukraine (focused on such technologies) is also to minimize, using existing technologies, discharges of used water. But, in contrast, the current practice in Ukraine is to bring industrial pollution to the level of certain standards for external sources instead of trying to constantly reduce emissions from industry. This practice in water management does not encourage a reduction in water consumption, as external targets can only be achieved by diluting wastewater. In addition, since a permit is issued for pollution of a particular environment, attempts are made to redirect pollution from the aquatic environment to another, such as the atmosphere, or to convert it into solid waste. That is why it is necessary to take into account the correlants and consider the introduction of an integrated permitting system, the introduction of which will significantly reduce financial costs. At the same time, the experience of wide implementation in Europe of emission standards based on advanced management technologies is useful for the environment and Ukraine.
Requires rationalization of pricing. The price of water should be transparent and realistic. It is necessary to introduce water meters for all water users, and the payment should be made in proportion to the amount of water used. The cost of water should correspond to the level of full reimbursement of all costs for investment, maintenance and operation of water infrastructure. Exceptions should be made for those who are unable to comply with these requirements.

When justifying the cost of water and the efficiency of its use, it is necessary to consider possible alternatives and reflect not only economic components, but also environmental and social factors.

Significant work has been done in recent years to develop new legislation. The new Water Code and special regulations for the protection of marine waters from pollution and clogging define the basic requirements for the protection of the marine environment. The lack of special norms and standards of sea water quality hinders control activities, permitting procedures and assessment of the state of the environment. At the same time the general specifications for surface waters are used. There is also a need to develop a common methodology for issuing permits for discharges into the sea, which could be used by regional authorities instead of giving specific tasks to research institutes. The new environmental legislation does not include funding mechanisms for environmental management.

National environmental authorities are fully aware of the need to integrate environmental policy development and management in coastal areas. Draft relevant documents on the implementation of the principle of integrated coastal zone management have been developed mainly within the framework of the Black Sea Environmental Program. The special needs of the marine environment should be reflected in special legislation on the protection of the marine environment. It should comply with relevant national and international norms and standards and include new mechanisms for the formation and replenishment of funds. Control over the operation, development and construction of new structures and facilities for the loading, transhipment and storage of petroleum products, chemicals and other hazardous substances needs to be strengthened. Ukrainian ports are equipped with water treatment plants for oilcontaminated waters and the necessary means to combat oil spills within its territory. The Ministry of Environmental Protection and Nuclear Safety and the Ministry of Transport have every opportunity to monitor activities in the coastal zone within the scope of their powers established by law. Improved management technologies and reporting on current, intermediate and final controls on the operation, development and construction of new structures and facilities for loading, transshipment and storage of petroleum products, chemicals and other hazardous substances need to be developed.

Increasing concerns about addressing both national and international environmental issues, conventions and strategies, and strengthening their links with many social and economic aspects of sustainable development must be given higher priority. This requires the improvement of 
information and methodological support, expansion of dialogue, development of communication channels. Achieving goals in this direction requires special programs and the use of adequate methodologies aimed at specific audiences, the integration of international environmental standards, reflected in many conventions ratified by Ukraine. Incorporation into national sociopolitical strategies will be significantly facilitated if the cognitive-informational aspects of the knowledge movement are streamlined.

To this we add that, as a rule, the monitoring of the marine environment is a by-product of the main activities of some agencies and research institutes, and these circumstances determine how it is carried out. According to national legislation, the Ministry of Environment of Ukraine is responsible for the overall coordination of monitoring processes that take place in the country at the national level, but, in practice, it can not participate in budget preparation to intensify all monitoring activities in the field of nature. The Ministry of Environment of Ukraine takes an active part in several international initiatives, such as the Black Sea Environmental Program, the Danube Program, and the Working Group on the Environment of the Black Sea Economic Cooperation. In addition, Ukraine has already signed some international agreements in this area, and the Ministry is now working to ensure their ratification and implementation. Therefore, applying the international agreements already signed by Ukraine and their existing structures, further management of the environment of the Black and Azov Seas should cover the entire catchment area. Ukraine should consider initiating a basin program and / or promoting closer cooperation between the Black Sea Environmental Program and all existing and planned programs for rivers flowing into the two seas, in order to ensure basin coordination of environmental management affecting the Black and Azov Seas. Adequate coordination mechanisms should also be developed for the Black Sea catchment area within the country.

In this regard, we have developed a set of measures for the implementation of the subsystem "Improvement of information and methodological support of water management processes."

The existing monitoring system is too fragmented: many institutions monitor a significant amount of pollutants, and outdated stations use incompatible methodologies. Often different institutions have to collect the same data because they cannot be exchanged due to data bank incompatibilities. Environmental audits of industrial enterprises should be used as a basis for the gradual development of an integrated permitting system covering water, air and waste permits. The organization of the various inspection services needs to be reviewed to improve their combined economic efficiency.

The amount of work required should not be underestimated, even taking into account all the experience of previous conferences, it should be used as an opportunity to involve many ministries, other government agencies, public and scientific institutions. In an economic depression, international environmental cooperation is certainly not a top national policy priority. In Ukraine, in addition, many managers, as well as the public, should pay more attention to environmental issues and international environmental cooperation, including their impact on other areas of activity, from the economy to health care. Coordination and cooperation between all institutions involved in the development and implementation of policy and management of international cooperation programs needs to be improved. Consideration should be given to establishing a special organizational structure for these purposes. An international task force should also be established, which will include, on a voluntary basis, representatives of partner countries wishing to assist Ukraine in its environmental activities. A clear focus on market measures and principles in the field of international cooperation is needed.

Groundwater monitoring needs to be improved. Individual monitoring networks, using different software products, generate significant amounts of data that accumulate in different information banks. As a result, the compatibility of monitoring data from different networks is very complicated. In addition, most monitoring data is not aimed at regulation, and in some cases it cannot even be used by regulators. Monitoring data are often collected and collected by regional authorities and are not available for decision-making at the state level. The Ministry of Environment of Ukraine is authorized to be responsible for the coordination of these monitoring activities in order to ensure better integration and control of water quality. The implementation of these provisions will not only save significant funds and harmonize the monitoring data obtained from different programs, but will also allow the full use of monitoring results for decision-making at all levels. The system and scale of monitoring networks in the field of water use need to be improved. Although various ministries and state committees have already set up several monitoring systems, their activities are aimed at achieving certain local goals. There is duplication of work, especially in the monitoring of chemical and bacterial parameters.

Providing the population with adequate drinking water that meets hygienic standards should be considered a priority. Therefore, public access to information on drinking water quality must be ensured. The use of water from relevant groundwater sources must increase significantly, and the protection of drinking water resources must be properly ensured.

Environmental certification plays an important role in strengthening the information and methodological support of water use management processes. Its implementation requires certain costs, so it must be objective, complete and useful for the business environment [11]. In Europe, there is a positive experience of voluntary environmental certification, implemented, for example, in Tuscany [12]. This helped to discuss policy measures aimed at environmental safety and increase the soundness of investment decisions.

The significant factor for decision-making is the value of information. Ukraine has a wide network of environmental monitoring, and it covers various executive bodies and scientific institutions. They are on the edge of surviving. Primarily because of broken ties 
with former Soviet partners and disintegrated monitoring system. It has also lost some methodological support, and suffers from severe budgetary constraints, while the activity of its various structural units is often duplicated. In order to reduce the cost of the monitoring system, it needs optimization. In the country, there are no procedures of self-controlling. The Ministry of Environmental Protection of Ukraine together with all executive bodies and the participation of all stakeholders should clearly create integrated coastline zone organization as an independent part of its new policy. It requires the creation of suitable tools for institutional cooperation and the involvement of academic staff, local business and the public to ensure integrated coastal zone management. A positive example of monitoring is the EMAS Regulation (Reg. 761/01 EC). It is an EU scheme implemented by the European Commission since 1993 and intended to integrate the Environmental Management System (EMS) [13]. There is a close connection between the implementation of the environmental management system and indicators of the ecological condition of the territory.

Given the semi-enclosed nature of the Black Sea, the high anthropogenic pressures and the vulnerability of its ecosystem, it is clear that only regionally coordinated action can actually improve its condition. In order to use new effective tools for managing the marine environment, Ukraine should participate in the development and implementation of a harmonized system of state port control in the Black Sea region (together with neighboring countries and entities) and, accordingly, in the development of a regional emergency plan.

Preferably, the environmental criteria of existing water regulatory or regulatory documents are based on the use of maximum permissible concentrations or levels of pollutants. Practically, until recently, these norms as regulatory criteria - are the only ones approved at the state level, which have scientific, methodological and analytical justification. Therefore, this requires the development of a new system of relative indicators to assess and forecast the effectiveness of water management, some of it should be introduced into the system of national accounts.

Regarding the implementation of the subsystem "Certification of industries and technologies, as well as regions by the factor of effectiveness of water management", in our opinion need to develop a universal application toolkit, reporting documentation forms, etc., which are recommended for different levels of government. At the same time it is necessary to provide reflection of a water trace and production of [14].

At present, there are questions about the possibility (or impossibility) of increasing and rationalizing the development of the strategic potential of Ukraine's economy, in general. It should be noted that currently the main source of information is the data of the State Statistics Service of Ukraine, Ministries of Economic and Regional Development of Ukraine, Ministry of Infrastructure, etc. and, as is known, the results of a comprehensive survey of state water farms, providing evidence in generalized form. The importance of primary data is determined by a system of indicators that should be used to assess the effectiveness of integrated water resources management [15]. Therefore, the development of passports is the subject of a separate scientific study.

\section{References}

1. Current Ideas on Sustainable Development Goals and Indicators // Rio 2012 Issue Brief Produced by the UNCSD Secretariat. 6, (2011).

2. Report of the World Summit on Sustainable Development. Johannesburg, South Africa, 26 August-. 4 September 2002. A/CONF.199/20, United Nations - New York (2002).

3. Burkynskyi B. V. Pryrodokorystuvannia: osnovy ekonomiko-ekolohichnoi teorii (1999).

4. Hoekstra, A. Water scarcity challenges to business. Nature Clim Change 4 (2014).

5. Estrela, Teodoro, et al. Sustainable water use in Europe. Office for Official Publications of the European Communities (2001).

6. N. Kovchun, V. Solodkyy Ensuring Sustainable Water Use in Ukraine. International Journal of New Economics, Public Administration and Law 1 (2018)

7. Liu, Yuqiong, et al. Environmental Modelling \& Software 23.7 (2008) .

8. Pahl-Wostl, Claudia, et al. Current Opinion in Environmental Sustainability 5.3-4 (2013).

9. Schoderer, Mirja, Jampel Dell Environmental Science \& Policy 111 (2020).

10. Raju, K. Srinivasa, Lucien Duckstein, and Cecile Arondel. Water Resources Management 14.6 (2000)

11. Jaung, Wanggi, et al. Journal of environmental management 212 (2018).

12. Daddi, Tiberio, et al. Journal of Cleaner Production 114 (2016)

13. Iraldo, Fabio, Francesco Testa, and Marco Frey. Journal of Cleaner Production 17.16 (2009)

14. Lambooy, Tineke. Journal of Cleaner Production 19.8 (2011)

15. Petit, Olivier. Current opinion in environmental sustainability 21 (2016) 